\title{
Alteración del concepto de etnicidad desde la experiencia de las tejedoras mapuche del sur de Chile ${ }^{1}$
}

\author{
Ramiro Gonzalez Rial ${ }^{*}$ \\ Andrés Haye \\ Pontificia Universidad Católica de Chile, Escuela de Psicología. Santiago, Chile
}

\begin{abstract}
Resumen: El caso de tejedoras mapuche de la IX Región de Chile nos permite reconsiderar los fenómenos de identidad cultural y etnicidad a la luz de las tensiones y procesos de subjetividad que median la construcción de memoria cultural. Se analiza tanto un escenario microgenético de los trabajos de identidad - como un escenario macrogenético, donde los procesos identitarios, las técnicas comerciales y religiosas del contexto mapuche se relacionan entre sí en permanente transmutación. Se discute el concepto de etnicidad con el fin de contribuir a ahondar en un fenómeno que está lejos de manifestarse como simple homogeneidad. Se realiza una discusión dando cuenta de la multiplicidad de tomas de posición en la experiencia de las tejedoras, enfatizando una mirada a la etnicidad como un proceso en permanente devenir, donde la memoria social del grupo reconduce una selección interesada de tradiciones orientando la construcción de una identidad potencial de cara al porvenir.
\end{abstract}

Palabras clave: identidad étnica, indígenas, psicología social, memoria social.

Los mapuche son el grupo indígena más numeroso en Chile. Si bien, históricamente han poblado el sur de Chile, los últimos censos indican que la Región Metropolitana es la más poblada por mapuches, seguida por la región de la Araucanía (INE, 2012). Existen diversas hipótesis acerca del origen de estos pobladores del sur de Chile: unas que consideran migraciones desde la zona amazónica o del Chaco, y hasta otras que plantean la afinidad de los mapuche con la cultura Tiahuanaco (Bengoa, 2003). Estas han sido desestimadas por los hallazgos arqueológicos en Monte Verde (cerca de la ciudad de Puerto Montt) que datan de unos 13000 años antes del presente y lo sitúan como el asentamiento humano más antiguo de Chile (Dillehay, 2004). En la región de la Araucanía, en las provincias de Cautín y Malleco (donde se encuentran los casos de los que hablaremos en este artículo) habitan las comunidades Mapuche, Mapuche-Pehuenche y MapucheLafquenche. Todas estas son reconocidas popular y ampliamente por la sociedad chilena bajo la categoría "mapuche". Dentro de estas comunidades la religión y el tejido artesanal mapuche son dos de sus pilares fundamentales para su identidad como pueblo histórico (Mege, 1990, 1997).

El tejido artesanal puede considerarse como un modo especial de memoria cultural, implicando un cultivo histórico de prácticas especializadas (técnicas de

1 El presente artículo ha sido posible por el financiamiento del Centro de Estudios Interculturales e Indígenas - ICIIS (FONDAP15110006), y del proyecto Anillos en Ciencias Sociales (CONICYT-PIA SOC1103).

* Autor correspondente: rggonzal@uc.cl producción y de intercambio) y de marcos normativos (estándares estéticos y criterios de pertinencia) que dibuja a través de generaciones un devenir de repertorios tanto de creación colectiva como de conceptualización de lo que en cada tiempo se considera parte de la tradición. Este concepto de memoria cultural se debe fundamentalmente a Halbwachs (1925/2004), especificado para el análisis de objetos culturales por Van Dijck (2004), y articulado con procesos de creación y subjetivación por Haye (2012). Considerado como memoria cultural, el tejido artesanal entraña una doble complejidad: una relación dinámica de conservación y cambio, atravesada por la articulación psicosocial de una identidad colectiva (un "nosotros") con una identidad personal, la de cada autora. Haremos énfasis en esta segunda complejidad. Cuando la identidad colectiva involucra procesos de adscripción, clasificación y diferenciación que hacen referencia a la idea de un grupo de origen común, se la denomina identidad étnica, etnicidad o simplemente grupo étnico. La idea de etnia como referencia a un origen común implica una categorización homogenizante de un grupo humano que muchas veces vela las tensiones identitarias que se dan en su interior. El caso de tejedoras mapuche de la región de la Araucanía de Chile nos permite reconsiderar estos fenómenos de identidad cultural y etnicidad a la luz de los conflictos que emergen a lo largo del camino de articulación psicosocial de una identidad, es decir, a la luz de las tensiones y procesos de subjetividad que median la construcción de memoria cultural.

Para el pueblo mapuche, en efecto, tanto el tejido como el rol de las tejedoras han ocupado un lugar de gran 
relevancia en la tradición y memoria del mismo (Mege, 1990). La actividad del tejido consistiría en una forma de recordar que se lleva a cabo por medio de prácticas sociales, que no sólo estructuran los contenidos de dichos recuerdos y sus marcos (Halbwachs, 2004) sino también los procesos intraindividuales que participan en esas formas de rememorar (Paolicchi, 2000). En el caso de estas actividades folclóricas, ese "nosotros" o identidad colectiva se pone en juego de generación en generación por medio de reglas o códigos tradicionales, es decir, comportan una normatividad que proviene supuestamente del pasado. Las costumbres relativas a la selección del material, la composición formal y la circulación social de los productos artesanales y obras folclóricas son puestas en juego y eventualmente problematizadas en la operación misma de transmisión de saberes y hábitos de la que depende la persistencia de una tradición, o más en general, la continuidad de las herencias culturales. La memoria cultural se suele considerar como una acumulación de diferentes productos que reflejan un marco de tiempo histórico, siendo apreciadas como memorias mediadas que forman parte de nuestras identidades individuales y culturales; es una colección de "actos creativos de la colección y producción cultural mediante los cuales la gente da sentido a sus propias vidas y a su conexión con la vida de los otros" (Van Dijck, 2004, p. 262). Por ello, la memoria cultural contiene como su propio mecanismo la problematización de las normatividades tradicionales para responder a la novedad de la experiencia. Pues en cada trabajo de tejido, así como cada proceso de producción folclórica, la tejedora ha tenido que resolver (de alguna manera, más o menos incompleta, pero siempre creativa) una articulación entre la norma dada desde el pasado, recibida como tradición, y las condiciones singulares del presente, entre las cuales debe destacarse el desarrollo social del material y de la técnica. Las fuentes de esta necesidad residen tanto en el plano macrogenético del ajuste técnico a cambios sociales, más circunstanciales o sostenidos, como en el plano microgenético del posicionamiento subjetivo, más crítico o sumiso, de cada autora individual. Por ello, la memoria cultural no consiste solo en colecciones de productos identitarios, sino más profundamente en un proceso de reconstrucción que permite constantemente revisar nuestras memorias para adoptar nuestras identidades (Gillis, 1994).

Entre tejedoras mapuche el tejido puede volverse escenario de diversos conflictos entre tradición e innovación, incluyendo tensiones entre los marcos colectivos que hacen posible un textil significante y los actos de creación concretos que lo hacen real. La autora del tejido artesanal tiene que articular de una manera distintiva su intencionalidad creadora con una presunta identidad étnica que le precede, pero al mismo tiempo es esta apropiación diferenciadora de la tradición lo que recrea dicha una presunción de etnicidad. En este sentido, cada autora, de manera silenciosa e incluso difícil de representar, para poder producir una representación étnica como una pieza de textil o cualquier enunciado identitario mapuche, ha debido tramitar subjetivamente una identidad colectiva, tomando una posición subjetiva no solo identificándose sino también resistiendo de diversos modos a las fuerzas homogeneizantes y a las categorizaciones dicotómicas que a menudo se deslizan bajo la bandera de lo étnico.

En el contexto actual de las tejedoras mapuche, este proceso de memoria en el que cultura, identidad étnica y prácticas tradicionales e históricas se van entrelazando, constituye un escenario complejo de variables entramadas. Escenario en que los procesos de subjetividad implicados invitan a reconceptualizar la cuestión étnica en un sentido dinámico de devenir y de construcción.

\section{Etnicidad e identidad étnica}

La noción de etnicidad tradicionalmente ha llevado consigo la idea de ser miembro de un grupo humano que se funda en una identidad común, que contendría los aspectos esenciales de dicho grupo y de sus miembros, y que provendría de un pasado común. El concepto es el de compartir una esencia subyacente a las variaciones observables tanto entre los miembros como a lo largo del tiempo. Autores como Denson, Lickel, Curtis, Stenstrom y Ames (2006) dan cuenta de cómo la idea de esencialidad transmite, en su uso, el sentido de una causa profunda e inalterable, permitiendo que las comunidades humanas sean concebidas como agregados sociales primordialmente homogéneos, poseedores de una importante similitud genotípica que une a todos los miembros del grupo más allá de sus infinitas diferencias concretas. Muchos autores, con tendencia a naturalizar la etnicidad, dejan ver en esta noción la posibilidad de hablar sobre grupos que tienden a "autoperpetuarse biológicamente", "compartir valores culturales fundamentales", "integrar un mismo campo de interacción y comunicación", constituirse con miembros que se identifican a sí mismos y que son identificados por otros "como conformando una categoría distinguible de otras del mismo orden" (Barth, 1976, p. 11). En este sentido, resulta interesante el trabajo de Saperstein, Penner y Light (2013) demostrando cómo este concepto ha estado históricamente ligado a las nociones esencialistas de raza y los esfuerzos teóricos que se vienen realizando en los últimos años para separarse de estas.

Otros autores proponen considerar un modo más dinámico o pluralista de entender a la etnicidad, para dar cuenta del creciente encuentro entre grupos diferentes dando lugar a sociedades multiétnicas (Brubaker, 2009; Schraml, 2014; Yinger, 1985). En esta misma línea, Jaspal y Cinnirella (2012) reportan que ha habido un cambio de perspectiva acerca de esta noción, abandonando la idea esencialista y explorando los procesos de construcción de identidades, e incluso de fabricación de etnicidades. Desde esta supuesta nueva perspectiva, el sentido identitario del grupo es reconstruido y revisado constantemente. Aún así, cuando estos autores hablan de "grupos", se da por supuesto la existencia de grupos definidos, incluso delimitados en función de rasgos geográficos, biológicos o culturales 
(Meer \& Tolsma, 2014; Okamoto \& Mora, 2014). En efecto, hablar de "encuentro" supone uno o más grupos diferenciados que, luego de constituirse como tales, comienzan a relacionarse. Además, se deja ver en estos trabajos que cada grupo tendría una identidad étnica determinada previamente a ese encuentro, lo que compromete una mirada homogenizante de la identidad (Kastoryano \& Schader, 2014). Este trabajo busca, en el plano teórico, avanzar pasos más decisivos hacia una mirada acerca de la etnicidad que pueda dar cuenta de ésta como una realidad dinámica y a la vez heterogénea.

La importancia de revisar el concepto de etnicidad se torna evidente en la medida en que también en la vida cotidiana de los grupos en general y de las tejedoras mapuche en particular esa noción de esencialidad homogenizadora acompaña la idea de etnia. En el contexto del tejido mapuche, y sobre todo en su circuito comercial, se juega fuertemente con este imaginario acerca de la existencia de un grupo homogéneo de tejedoras y de textiles. Profundizando en el estudio de este circuito y la cotidianidad de sus participantes, no se puede dejar de interpelar a estos constructos y de cotejarlos empíricamente.

\section{Hacia un enfoque dinámico de la etnicidad}

Especialmente en antropología y sociología se han realizado numerosos estudios enfocando la etnicidad no como cosa sino como relaciones cuyo contenido se fragua en la particularidad de su "construcción histórica" (Comaroff, 1994). Estos estudios muestran que la identificación étnica refiere al uso que "hace una persona de términos raciales, nacionales o religiosos para identificarse y, de ese modo, relacionarse con los otros" (Oliveira, 2007, p. 49) y analizan los mecanismos de identificación que reflejan la identidad como proceso. Varios de estos trabajos o informes muestran cómo son esos procesos que llevarán a distintas formas de identificación. Ejemplos clásicos de esto son los estudios acerca de los Lapones de Noruega que revelan cómo el status y los estigmas sociales influyen en los cambios de identidad étnica (Eidheim, 1976) o el papel que juega el nicho ecológico y la adscripción a una nueva identidad por parte de los fur en el Darfur Occidental (Haaland, 1976). Estos y otros estudios acerca de etnicidad e identidad étnica explican los cambios identitarios a nivel macro e invitan a que, desde la psicología, ahondemos en la experiencia del sujeto y en los procesos de subjetividad que acompañan esos movimientos. En el plano empírico, la presente propuesta indaga en los procesos subjetivos de toma de posición ante cambios identitarios macrogenéticos, que están involucrados en la respuesta de los sujetos a su propia adscripción étnica que realzan el aspecto reconstructivo de la identidad étnica en contraposición a la idea esencialista que clásicamente se ha ligado a ella.

En psicología social se ofrecen perspectivas que permiten pensar la esencialidad relacionalmente, que dan cuenta tanto de la flexibilidad situacional de las identidades sociales (Tajfel \& Turner, 1979) como de las condiciones de emergencia del esencialismo en la atribución de identidad que realizan los sujetos en su vida cotidiana. Desde la psicología, en particular los estudios sobre entitatividad dan cuenta de esos procesos de categorización en los que estarían arraigadas ciertas disposiciones a esencializar tanto al grupo ajeno como al propio. Fue Campbell (1958) uno de los primeros en teorizar acerca de ella en el sentido de una percepción de grupos como "entidades" significativas, o al menos unidades discretas a las que se les pueda atribuir una significación. La percepción de un grupo como entidad homogénea se produciría en distintos grados y esta variación puede ser empíricamente examinada. Yzerbyt, Corneille y Estrada (2001) sugieren que, en este proceso de percepción, participarían dos tipos de atributos grupales. En primer lugar, la semejanza grupal, con sus múltiples facetas de la homogeneidad, similitud, tamaño, proximidad etc. Dasgupta, Banaji y Abelson (1999) han reportado evidencia de cómo los sujetos tienden a atribuir intenciones y comportamientos homogéneos a grupos compuestos por miembros con similitudes observables. En segundo lugar, la organización grupal (interdependencia, interacción, objetivos) genera similitudes funcionales. Gaertner y Schopler (1998) han mostrado cómo, en la emergencia de entitatividad, la competencia intergrupal tiene un impacto más directo en el favoritismo al propio grupo. Brewer, Weber y Carini (1995) mostraron el papel que juega la interdependencia en la percepción de entitatividad, por ejemplo: grupos que persiguen un objetivo común (como los grupos de competencia) son percibidos como más homogéneos que aquellos que no compiten. En síntesis, la atribución de rasgos grupales presuntamente esenciales a los miembros de un grupo parece depender de condiciones que favorecen una percepción homogeneizante de dicho grupo. Si bien estos estudios no abordan aspectos subjetivos de los procesos que en cada caso conducen a esa percepción, sí muestran claramente el movimiento de homogeneización que implican ciertas tareas cuando está en juego la construcción de un "nosotros" o identidad grupal frente a otros grupos. Desde la psicología social, por lo tanto, se enfatiza el contexto intergrupal para dar cuenta de la entitatividad como una propiedad que no es del grupo social en sí, sino que depende de las relaciones con otros grupos, determinándose así desde el punto de vista del otro. La esencialización se realizaría desde afuera.

Cabe notar que si bien el contexto intragrupal de relaciones sociales no es fuente directa de entitatividad, los procesos individuales, interpersonales y colectivos en el marco de una comunidad o grupo étnico esencializado desde el punto de vista del otro pueden verse configurados desde arriba por la perspectiva que sobre la propia condición social tienen actores, grupos y voces relevantes. En este sentido, la construcción del grupo como entidad individualizable hace posible un ejercicio de dominación y subordinación, y es en sí mismo muchas veces expresión de jerarquías sociales. Sin embargo, las relaciones entre entitatividad y poder pueden ser más complejas. También los sujetos que se identifican con una determinada condición 
social aplican sobre sí mismos el punto de vista del otro que les permite auto-esencializarse, promoviendo homogeneidad y estabilidad desde el interior del grupo y de los sujetos que lo componen. Esta aplicación desde abajo de una perspectiva esencializante consiste también en un ejercicio de poder sobre la colectividad, a veces resistiendo prácticas de entitatividad predominantes, a veces conduciendo el proceso reforzando o privilegiando unas voces sobre otras dentro del grupo. Igualmente, desde arriba o desde abajo, la representación del grupo como entidad implica adoptar el punto de vista del otro, solo desde el cual el proceso social puede verse como algo determinado - siguiendo el argumento dialógico de Bajtin, 1982. Ese otro, ese afuera puede ser tanto otro grupo como un nuevo proyecto de identidad del grupo propio. En el caso de las tejedoras cuya cotidianidad ha sido analizada, puede pensarse en la emergencia de entitatividad, diversos grados, en el contexto de las relaciones sociales intergrupales que atraviesan los quehaceres propios del circuito textil mapuche. Así, al organizarse intragrupalmente como tejedoras, con sus objetivos de aprendizaje y comercialización, estas mujeres buscan recobrar o construir subjetivamente una identidad colectiva desde el cultivo personal de una tradición común, y al mismo tiempo posicionarse en un mercado que, a su vez, les devuelve esta categorización étnica de "tejedoras mapuche" desde el contexto intergrupal de relaciones con comunidades no mapuche.

Desde nuestra perspectiva, procesos cognitivos (percepción, clasificación, categorización, comparación etc.) involucrados en la emergencia del esencialismo, que la psicología permite describir en sus mecanismos generales, forman parte de procesos concretos de tomas de posición de un sujeto en relación con otros, articulando las categorizaciones e identificaciones con un sentido particular en un contexto local específico. A estos procesos los denominamos movimientos de subjetivación, y en este trabajo consideraremos las dinámicas y tensiones involucradas en la toma de posición de las tejedoras en su relación con la tradición mapuche y los contextos actuales de tejido, comercio y vida cotidiana.

\section{Tejedoras mapuche de la Región de la Araucanía en Chile}

La discusión aquí presente se basa en un trabajo de campo realizado durante el 2010 y 2011 con cuatro casos principales de tejedoras mapuche y algunos talleres donde se enseña el arte textil. Los cuatro casos corresponden a mujeres que se reconocen como mapuche y se encuentran entre los 45 y 55 años de edad. Estas mismas mujeres imparten talleres a otras mujeres de sus zonas, estas últimas consideradas como casos secundarios que sirvieron para contrastar la información que obteníamos de las cuatro tejedoras principales. En estas cuatro mujeres y los circuitos textiles y cotidianos donde ellas se mueven se pudo observar cómo la actividad textil mapuche se encuentra en un contexto atravesado por prácticas culturales, comerciales y religiosas que ponen en tensión las nociones esencialistas de la etnicidad, basadas en un principio homogeneizante de identidad.

El actual auge popular del tejido mapuche y las organizaciones que promueven el comercio de esta actividad entregan una imagen esencialista o "pintoresca" de esta actividad, y presenta a sus integrantes bajo una imagen esencialista o incluso naturalista de "lo mapuche", como si se tratara de un grupo homogéneo de tejedoras cuyos productos son "ancestrales o tradicionales". A esto se suma el éxito del comercio de lo étnico o de "etnomercancias" (Comaroff \& Comaroff, 2012) de las últimas décadas, llegando a venderse con cierto furor en los mercados de Europa y de los Estados Unidos de América. Gran parte de ese éxito en la demanda del tejido mapuche y de que el número de tejedoras haya aumentado en el último tiempo, se debe a la aparición en escena de organizaciones de tipo fairtrade o precio justo. Ellas se encargan no sólo de promover la venta de tejido dentro y fuera de Chile, sino también de "capacitar" a mujeres mapuche por medio de talleres en técnicas de telar y diseño.

El tiempo de estadía y el trabajo de campo realizado con algunas de estas tejedoras de la región de la Araucanía permiten apreciar no solo la complejidad sino también lo conflictivo que resulta el uso de la etiqueta de "tejedoras mapuche" como si se estuviera frente a un grupo homogéneo. Esta es una idea cultivada por algunos personajes dentro del circuito, sobre todo de las organizaciones de precio justo. Sin embargo, etiquetas como "tradicional" o "mapuche" generan una gran tensión cuando se pone en juego entre las mismas participantes. Por un lado, la mayoría de ellas son nuevas tejedoras y sólo conocen los modos de tejer que les enseñan en los talleres, estilos que en su mayoría poco tienen que ver con el modo en que se tejía históricamente. En este punto juega un papel importante la idea de innovación y acomodamiento a las necesidades del mercado, por lo que las organizaciones imparten talleres a cargo de diseñadoras ajenas a la comunidad mapuche, introduciendo nuevas reglas de tejido. Por otro, es interesante el juego que se produce con el grado de identificación étnica. Muchas de estas mujeres, que se reconocen a sí mismas como mapuche, profesan hoy otras religiones contrarias a la cosmovisión que históricamente ha sostenido este pueblo. En algunas otras, el autoreconocimiento como mapuche es algo nuevo en su vida y recién hoy están descubriendo esta parte de su identidad luego de mucho tiempo de ocultamiento (para evitar ser discriminadas por el resto de la sociedad, sus padres y abuelos no las educaron en la cultura mapuche). Finalmente, y no se trata de un número menor de mujeres, su adscripción como mapuche aparentemente no va más allá de una etiqueta heredada por algún antepasado indígena y al parecer, en el presente, esta adscripción no implica un modo de vida muy diferente al de otro campesino no mapuche de la misma región.

El contexto actual del tejido mapuche se caracteriza por constantes cambios, y por tanto abre la pregunta sobre 
qué procesos identitarios individuales y colectivos despliegan las tejedoras, y especialmente cómo dichos procesos se articulan entre sí en distintos niveles. Si se atiende a los discursos dominantes en el circuito del textil mapuche, no se advierte conflicto producto de los cambios sociales ni tampoco se reconoce la complejidad de las identificaciones étnicas, sino un circuito funcional de transformación homogeneizante de la tradición ancestral en productos comercializables, donde la subjetividad de las tejedoras no tiene lugar. En cambio, en el discurso de estas mujeres los cambios sociales están asociados a desajustes y desplazamientos entre niveles de identificación, tornándose problemático el trabajo subjetivo de construcción de identidad coherente entre los planos colectivo e individual. En el marco de permanentes modificaciones, diferenciaciones y resistencias culturales que caracterizan la macrogénesis de la actividad textil mapuche, cabe entonces preguntarse en qué consiste lo que típicamente se denomina como "étnico" en este ámbito. Pretendemos mostrar que las construcciones identitarias entran en tensión a través de la misma práctica artesanal, más allá y más acá del impacto general de los procesos de modernización sobre las identidades; este último, en efecto, no implica redefiniciones identitarias y ajustes subjetivos inmediatos, sino que los cambios sociales macrogenético son también tramitados, organizados y resistidos en la microgénesis de una actividad atravesada por posicionamientos subjetivos diversos. A continuación se analiza cómo resuelven esta mujeres esa tensión, ya que al asumirse como parte de un grupo frente a otro, dichas tensiones adquieren ribetes vitales y singulares a nivel religioso, cosmológico, económico y también en lo cotidiano de sus quehaceres. El análisis se realiza sobre dos escenarios que surgieron de la etnografía: el de la relación entre identidad y la técnica misma del tejido, y el de la relación entre procesos identitarios y las técnicas comerciales y religiosas del contexto mapuche.

\section{Identidad y técnica textil mapuche}

El primero de los escenarios al que nos referiremos es la tarea misma de realización del tejido, la creación técnica de una pieza textil. Según Comaroff (1994), la construcción de un sentido de etnicidad es económica, política y también estética: "implica simultáneamente, la producción tanto de objetos como de sujetos" (p. 209). Este último punto es central aquí, puesto que los modos de producción en este contexto están en permanente tensión con la identificación étnica de cada tejedora, al mismo tiempo que el quehacer influye sobre su construcción de identidad. Se propone aquí, siguiendo los estudios en el arte textil mapuche de Mege (1987, 1989), que este fenómeno se pone en evidencia en dos aspectos relacionados con la realización del tejido: la materia o sustancia del textil y las representaciones que allí se plasman.

Por el lado de la materia o sustancia, según Mege, la elección del material para la construcción del tejido no es azarosa, influyendo en la calidad y la técnica de preparación de la lana según lo que se busque tejer o para quién se realice. La creación es un proceso a la vez intencionado y atravesado por la contingencia, por la confluencia de múltiples factores a los que se ajusta la autora en el devenir de un proyecto específico. Así, la producción del tejido no es ni mecánica ni aleatoria. ¿Cómo entender el carácter propio de estas relaciones? En particular, Mege destaca, entre los factores de (in)determinación, el para qué y para quién se teje. Siguiendo a Bajtin $(1982,1989)$, consideramos que este proceso, al estar dirigido hacia alguien y con un propósito en la relación con ese otro, implica tomar una posición subjetiva. Esa elección de la materia y su preparación van pensadas hacia otro, pero también es de un otro que se han recibido los secretos de la preparación y también en conformidad a una tradición o regla de tejido. Siguiendo la teoría del discurso de Bajtín (1989), distinguimos tres planos de posicionamiento: ya en la aparentemente simple elección del material se establece una toma de posición, además de en relación con un otro receptor del tejido, frente a un otro pasado (por ejemplo, frente a la maestra), y al mismo tiempo de cara a un otro tercero (por ejemplo, la tradición o regla comercial convencional).

Según quién me pida, porque a mi mami le gusta el rosa para el nguillatún ${ }^{2}$... y ese se logra con tintura nomás... pero la [nombre de la fundación] no me acepta esos colores. La ancianita que me enseñó el trariwe también tenía de ese color [rosado]. Así que pal nguillatún así y a la fundación estos [señalando los hilados naturales], sino no se vende...". (María, tejedora de Almagro)

La tensión en este punto se pone de manifiesto cuando las normas vienen de un otro que representa un legado más tradicional, en comparación con nuevos mandatos como los religiosos o comerciales.

En cuanto a las representaciones que se plasman en el tejido, según Mege lo que se plasme aquí mediante símbolos y colores depende de su futura función y de la persona a quien vaya dirigido (hombre o mujer, clase, jerarquía, etnia). Ese proceso de representación permite contar algo u ocultarlo, nada es azaroso y todo tiene una intención por parte de la creadora. Según Mege (1990):

La tejedora que con anterioridad transmitía en sus textiles mensajes de acuerdo a un estricto código de significación, actualmente mezcla los símbolos por conveniencia económica, lo que produce incoherencias, expresiones contradictorias o hasta absurdas. Es tentador pensar que, aparte de la evidente estrategia económica que persigue la actual producción artesanal - es decir, vender lo que busca el comprador... tal vez se persiga un fin lúdico, un juego que consistiría en bromear con los símbolos textiles

2 Ceremonia religiosa mapuche.

3 Faja tejida que se utiliza en la cintura del hombre o mujer. 
a costa de los compradores y de los consumidores. (p. 60)

$\mathrm{Al}$ igual que en la elección de la materia, la técnica de representación implica tomar una posición frente al proceso que se utilizará, según lo que se quiera decir, a quién y sobre quién.

Teniendo en cuenta estos aspectos materiales y representacionales, podríamos advertir que la resolución de estas disputas y su articulación con procesos identitarios es un tanto diversa: uno puede observar en algunas tejedoras cierta actitud de resguardo y orgullo resistiendo a las nuevas reglas de tejido dictadas por el fairtrade, llegando a utilizar productos industriales con tal de poder reproducir viejos modos de tejido. En palabras de Estela, una tejedora de Puerto Saavedra, "¿cómo no seguir haciendo con esos colores? si eran los colores que usaban mis abuelas... si ya mi abuelita usaba tintes industriales para poder hacerlos". Esta decisión o toma de posición les lleva a quedarse fuera del circuito comercial por no seguir las nuevas reglas, ya que las organizaciones de precio justo son estrictas en la exigencia del uso de materiales naturales y no se los reciben para ser vendidos. Estos tejidos que continúan lo típico pero mediante materiales artificiales no encuentran fácilmente el modo de ser vendidos, por lo que frente a la necesidad de dinero, sucumben ante lo pedido por las organizaciones. Cuando esto último sucede, aquellas que respetan el significado sagrado de los textiles los tejen sin plasmar símbolos importantes para evitar que los compradores ajenos los profanen con un mal uso de ellos.

El lukutue es sagrado, es un pensamiento muy sagrado, y ponen otra cosa: la estrella, la luna que también se dibuja y así otro dibujo pero no el lukutue... ahí se están vendiendo a ellas mismas, entonces uno para vender... yo para vender... no me vendo. Yo innovo, vendo productos más llamativos, más coloridos... (Estela, tejedora de Puerto Saavedra)

Estos ejemplos hablan de tejedoras con un extendido conocimiento de religión y tradición mapuche ligada a una práctica familiar antigua. Otros casos implican a mujeres que pertenecen a una generación en que sus padres o abuelos no transmitieron una "identidad mapuche" para que "eviten" ser discriminadas, y así facilitar una mejor aceptación en la sociedad no mapuche. Estas mujeres, en la búsqueda de sus "raíces", encuentran en la actividad del tejido, y sobre todo en los talleres de las fundaciones, un modo de reencontrarse o descubrir este aspecto negado de su historia:

Mis padres y abuelos no me quisieron enseñar nada... no me dijeron que era mapuche para que

4 Figura antropomorfa presente en la iconografía mapuche. Puede ser observado en la Figura 1 en la imagen del tejido de la ciudad de Tirúa. no me dijeran india los compañeros y profesores. En el taller aprendi dibujos y diseños mapuche y conoci a otras mujeres como yo (Tejedora de Nueva Imperial).

Para ellas, el nuevo modo y las nuevas reglas de tejido (colores naturales aunque no sean los típicos mapuche) aprendidos bajo estas condiciones es lo que las identifica como tejedoras mapuche. Esta nueva representación o identidad textil mapuche es, estéticamente, más homogénea que en años anteriores. Esto se debe a que diferentes fundaciones, en diversas localidades de Chile, imparten similares reglas y contenidos simbólicos para sus participantes, lo cual lleva a que encontremos los mismos textiles en zonas que antes diferenciaban claramente sus estilos de tejeduría (ver Figura 1).

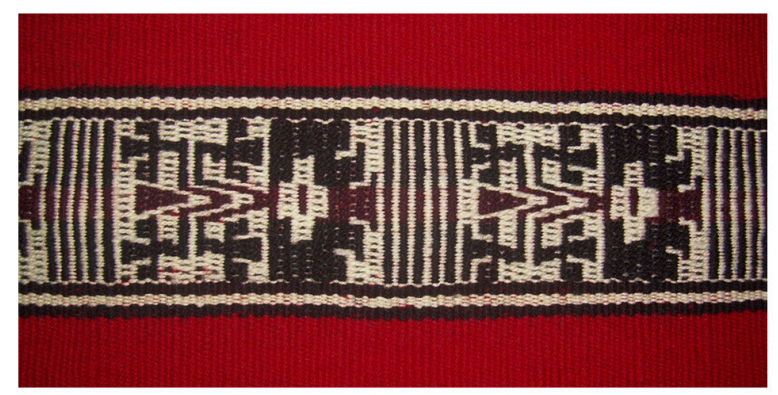

Tejido de la ciudad de Tirúa

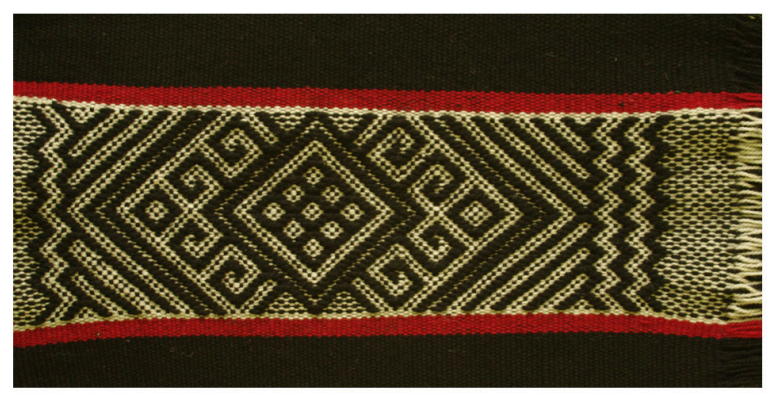

Tejido de la ciudad de Valdivia

Figura 1. Imagen de dos textiles vendidos como ornamentos de pared. Observamos que ambos utilizan los mismos colores siendo de regiones alejadas entre sí. Tradicionalmente podían identificarse diferencias entre ciudades por el uso de colores característicos en cada territorio ${ }^{5}$

\section{Técnicas comerciales y religiosas del circuito textil mapuche}

Este quehacer del tejido recién descrito y su tarea de producción tienen lugar, tal como remarca Comaroff (1994), "en los pormenores de la práctica de la vida diaria" (p. 208). La experiencia etnográfica con estas tejedoras arroja una gran cantidad de información acerca de la cotidianidad de estas mujeres y sirven para complementar lo

5 Para mayor detalle del uso de colores ver Mege $(1990,1992)$. 
observado en torno a la práctica misma del tejido. Aquellas tensiones en las tomas de posición y en la adscripción a diferentes identidades descritas anteriormente también se observan en estos otros escenarios cotidianos. Entre esos "pormenores" de la vida diaria podríamos resaltar las tensiones identitarias que surgen frente a la aparición de instituciones religiosas y comerciales. Un ejemplo es la participación de algunas tejedoras en iglesias evangélicas, lo cual les implica dejar de tejer representando iconos simbólicos de la religión mapuche porque, a la luz de nuevos líderes religiosos, aquellos símbolos serían "diabólicos":

El pastor de la iglesia me dijo que eso [señalando el lukutuel] es diabólica... y que esa cuestión es un brujo. Es que Dios no va a mandar a hacer las cosas malas... por eso mismo yo me abstengo de hacer muchos trabajos. No quiero meterme mucho en ese tejido, lo enseño, pero yo lo miro como un tejido (Verónica, tejedora de Pillumallín).

Otro ejemplo son las diferencias que se producen entre aquellas que se niegan a incorporar cambios, si es que estos modifican pautas tradicionales, en contraste con aquellas que incorporan o se acomodan a las nuevas reglas en pos del éxito comercial:

Van cambiando y metiendo dibujos que no deben meter. Eso es lo que han hecho como tus has visto en la [nombre de la fundación], que lo hace muy poco y muy mal ñimin ${ }^{6}$. Está también haciendo la [nombre de otra fundación] que no hace ñimin, el [nombre de la fundación] no hace ñimin para que estamos con cosas. El lukutue es un dibujo que solamente puede usar la machi, pero acá ya en la novena se ha pisotiado mucho porque culpa de la necesidad y la gente lo compra pero no sabe lo que lleva (Estela, tejedora de Puerto Saavedra).

Se ha presenciado en el trabajo de campo que estas tensiones no dejan indiferentes a las participantes y propician configuraciones subjetivas complejas, incluyendo reveses o dobleces de las posiciones identitarias que permiten a una tejedora dotar de un sentido concreto su adscripción o categorización étnica. Por ejemplo, Estela, quien se niega a vender lo tradicional, acepta que por necesidad a veces debe tejer mantas o frazadas comerciales. Las diversas tácticas de articulación identitaria que hemos podido distinguir a través del tejido no dependen solamente de características individuales, sino que están presentes virtualmente en cada tejedora, pudiendo desarrollarse en diferentes situaciones de interpelación o interlocución distintos procesos de identificación con la propia etnia.

Esta flexibilidad o movilidad identitaria se puede entender en comparación con la definición que Barth (1969/1976) hizo hace algunas décadas sobre el concepto

$\overline{6}$ Técnica de tejido por medio del telar mapuche. de grupo étnico. Él señala que este grupo se define no por sus características objetivas o manifiestas (la lengua, la cultura, la vestimenta y otras), sino por la demarcación de fronteras étnicas, esto es, por las diferencias objetivas que los propios actores definen como significativas para sí y para otros. De esta manera, la característica fundamental de la existencia de un grupo étnico es la autoadscripción y la adscripción por otros: "Una adscripción categorial es adscripción étnica cuando clasifica a una persona de acuerdo con su identidad básica y más general, supuestamente determinada por su origen y su formación" (Barth, 1969/1976, p. 15). Sin embargo, la noción de una identidad básica y más general debe ser discutida, porque como se ha visto en este caso, encontramos diversas adscripciones y tomas de posición respecto de las mismas adscripciones al interior de este grupo que, a su vez, es presentado públicamente como homogéneo. Esta paradoja se apoya en el contraste que genera la adscripción "esencial" que le otorgan las organizaciones comerciales, así como la valoración negativa desde las iglesias evangélicas, con la multiplicidad de posiciones identitarias que asume cada mujer en el marco de la actividad artesanal del tejido mapuche.

\section{Discusión}

$\mathrm{Al}$ analizar el circuito comercial y de enseñanza del tejido en estos grupos de la región de la Araucanía queda la impresión de que la etnicidad funciona simplemente como una etiqueta, y no en el quehacer mismo de la mujer. En efecto, en el trabajo de campo con tejedoras de taller, se ha observado que no hay interés en que ellas entiendan el significado de lo que están tejiendo, sino que el material cumpla con una estética determinada. El modo en que se enseñan las reglas de construcción textil y la simbología que se transmite en los talleres, en su mayoría, se hace sin profundizar en su significado. "Esto es así porque así es el tejido mapuche." Frases como ésta suelen escucharse cuando se intenta ahondar en su significación.

Vemos así cómo una noción esencialista de etnia, iconografía y narrativa tradicional que apelan a un pasado común y prácticas de formación de un etnodiscurso sobre el textil mapuche (etnomercancía) operan concertadamente para producir una naturalización (de-historización y de-subjetivación) de la etnicidad. En algunas de las tejedoras mapuche, su propia condición de tejedora-mapuche está siendo redefinida en los circuitos comerciales y religiosos del arte textil sin que ellas tengan otro posicionamiento que el de realizar la paradójica tarea que se les ha encomendado: reproducir una identidad textil fija, es decir, fijada por la confluencia actual de múltiples factores sociales que contextualizan el quehacer de cada tejedora, en el marco contingente de una modernización neoliberal en pleno proceso. La historicidad, e incluso la modernidad de la identidad étnica de la tejedora queda paradojalmente negada. Puede especularse que la modernización de la actividad textil a través de los talleres, al cosificar el tejido en piezas de textil dentro de determinados circuitos, ha debilitado la 
densidad subjetiva del tejido, homogeneizando la identidad étnica y al mismo tiempo diluyendo la autoría de la tejedora. La noción de etnicidad funciona aquí anclando una identidad social de estas mujeres a un pasado originario que se les oculta, cerrado como está a ser significado, interrogado, investigado. Subjetivamente, su etnicidad se les ha vuelto natural, en el sentido de algo ya dado, resuelto, no algo por venir ni un desafío.

Diferente son los casos de algunas tejedoras ancestrales, mujeres que aprendieron de sus familiares antecesoras, de quienes han adquirido algo más que la mecánica de la tarea textil. Tanto en la práctica del tejido como en la participación del intercambio comercial, estas mujeres ponen en juego todo un repertorio de identidades, de modo que la relación entre autoría y etnicidad es vivida como subjetivamente problemática. Encontramos algunas que parecen reafirmar su identidad mapuche, también aquellas que dicen que esta práctica les ha ayudado a descubrir parte de una identidad ocultada por años, y otras tantas que aparentemente no tienen una definición clara de su identidad cultural y étnica. Ciertamente, estas modalidades diversas de identificación y posicionamiento subjetivo se observan también entre tejedoras de taller, aunque de manera más atenuada y menos explícita, dado el carácter aproblemático e incluso funcional de la adscripción étnica. El trabajo de campo permitió observar diversas identidades mapuche en distintas tejedoras, así como múltiples posicionamientos subjetivos respecto del tejido mapuche (como autora, como mapuche, como mujer, como tejedora, como evangélica etc.) que no se dejan resolver en una identidad. Vemos cómo una etiqueta étnica puede recubrir una búsqueda en diversas direcciones, una inquietud más que un hábito, y una multiplicidad de matices subjetivos más que una identidad homogénea que subsume a cada tejedora de manera equivalente. La heterogeneidad subjetiva de las identificaciones étnicas, que es recubierta por categorías culturales o etiquetas que circulan socialmente en las tejedoras ancestrales es evidente, pero la homogeneidad objetivada que se ha observado entre tejedoras de taller nos parece que puede entenderse también como un efecto recubridor de la identidad respecto de la diferencia. Como un medio para esclarecer nuestra propuesta, resulta especialmente relevante discutir un concepto de etnicidad vinculado a la construcción de identidades que han propuesto recientemente John y Jean Comaroff:

Hay que contemplarla como un repertorio laxo y lábil de signos mediante los cuales se construyen y comunican las relaciones; un repertorio a través del cual se torna sensible una conciencia colectiva de la similitud cultural; algo que sirve como referencia para que los sentimientos compartidos adquieran sustancia. Su contenido visible siempre es el producto de condiciones históricas que, en medida diversa, inciden sobre la percepción humana $y$, al hacerlo, dan forma a las motivaciones, los significados y la materialidad de las prácticas sociales. (Comaroff \& Comaroff, 2012, p. 65)

Observemos que, gracias a un repertorio amplio y diverso, se torna sensible una conciencia colectiva de la similitud cultural. Las tejedoras forman un grupo heterogéneo; unas que mantienen cánones de tejidos más antiguos y otras que siguen las nuevas reglas aprendidas en talleres actuales. Estas dos modalidades acaso son una de las varias oposiciones posibles en el seno del tejido mapuche actual. El contraste entre diversas tejedoras es manifiesto en el discurso de las mismas, a través de sus opiniones acerca de los trabajos de otras tejedoras. En el trabajo de campo, dicho contraste entre tejedoras ancestrales y de taller ha permitido comprender un amplio y diverso ámbito de variación de las posiciones subjetivas desde dónde se identifican estas mujeres. Debajo de la similitud cultural que nos entregan los circuitos del textil mapuche, existe en la actividad de estas tejedoras una pluralidad de voces y de tensiones subjetivas que convergen en una compleja búsqueda identitaria. La "conciencia colectiva" en torno al tejido engloba o recubre una multiplicidad que es efectiva, pues está produciendo cambios en el modo de tejer y de lo que se teje, independientemente de si esta fuerza cultural centrífuga (Bajtin, 1989) es reconocida o no con claridad y distinción en la conciencia de la tejedora. Proponemos, por ello, reemplazar la noción de una conciencia colectiva de la similitud cultural por la metáfora de un signo o una imagen colectiva (diseño textil tradicional) que recubriera la diversidad cultural, amparando o sometiendo las diferencias subjetivas bajo una identidad étnica.

Asimismo, proponemos reconceptualizar la similitud cultural en términos plurales, como similitudes, pues siguiendo la teoría de la categorización social (Tajfel \& Turner, 1979) y de la entitatividad (Campbell, 1958) una relación de similitud no depende de un único punto de referencia (que, en la cita, da sustancia o soporte a los sentimientos compartidos) sino que puede generarse tantas relaciones de similitud distintas cuantos posicionamientos identitarios y construcciones de la etnicidad divergentes, recubriendo la experiencia autoral de cada tejedora. Bajo la etiqueta de "tejedoras mapuche" encontramos mujeres mapuche con alto grado de identificación étnica y otras que pasaron toda su vida sin saber que eran mapuche. Lo mismo sucede con la etiqueta de "textiles mapuche", porque nos encontramos con nuevos textiles que contradicen antiguos modos de tejer, o tejidos realizados al nuevo modo a sabiendas de su autora que estos no son los tradicionales ni los originales pero que son medios de identificación para aquellas que están asumiendo una nueva identidad. En síntesis, proponemos conceptualizar la etnicidad como un operador cultural que, a partir de diferencias presentes y diferencias pasadas que perviven en el presente, construye similitudes, o sea, produce colectividades. En esa construcción de las imágenes identitarias, normas 
textiles y representaciones étnicas no hacen sino resumir y orientar la actividad en función de las similitudes que pueden generar.

Así, la relación que estamos proponiendo entre la etnicidad y el repertorio heterogéneo y flexible de signos puede conceptualizarse siguiendo la relación que se establece entre lo técnico y lo étnico en el trabajo de Stiegler (1994). Según este autor, reelaborando críticamente ideas de Gourhan, Simondon y Heidegger, deberíamos "estudiar la relación entre la técnica, cuya esencia es la tendencia universal, y lo étnico, cuya manifestación, de la que es la concretización particular, recubre la universalidad" (p. 71). Stiegler (1994) plantea un modo interesante de pensar lo étnico como la performatividad de un interior virtual en el proceso abierto de la exteriorización técnica, cuyo rendimiento no es otro que la individuación del devenir técnico, que la diferenciación del futuro:

La unidad técnica es esencialmente momentánea, en perpetuo devenir, nunca es adquirida porque ella misma no procede de un origen que sería común a los hombres que componen esta etnia: la unidad étnica es convencional, sin otro origen que no sea mítico, y no existe, contrariamente a la teoría de los círculos concéntricos, un genio étnico de la ciencia que sería él mismo el hecho de una raza originaria "más dotada" que las demás. (p. 87)

Stiegler (1994), citando a Gourhan, sostiene que la etnia es más un devenir que un pasado, nada de originario habría en ella más que lo original de concretizar una tendencia técnica. No habría un "genio de la invención" sino una sistematicidad (conjunto de sistemas técnicos, no un solo sistema) que "se realiza en un acoplamiento del hombre y de la materia" (p. 72). Lo étnico se jugaría en lo objetivable de las técnicas, manifestándose a través de los matices que ésta adquiera según cada unidad o grupo. Eso sería lo propio de cada pueblo, el modo y los usos de las prácticas en que se juega la construcción del nosotros objetivando una tendencia técnica que sería universal. Lo interesante, a efectos de guiarse por la propuesta de Stiegler (1994), es que esa construcción es un movimiento progresivo de conquista del medio externo, que posee también objetos e ideas de grupos humanos diferentes, por parte del medio interno o "memoria social" (p. 90). Esa conquista o apropiación del medio externo inscribe en un proceso de individuación y diferenciación a la unidad de cada pueblo que es la etnia, quien a su vez es la que realiza dicho movimiento de objetivación de la tendencia. La etnicidad sería entonces el proceso de construcción del marco cultural de las formas y variaciones técnicas de un ambiente propio que recubre con una significación colectiva particular la tendencia transformadora de la técnica misma del tejido, así como las técnicas de significación y de mercantilización de los textiles.
Retomando la cita de los Comaroff que estábamos comentando, cabe detenerse en la idea de que el repertorio de signos en el que consiste una etnia es producto de situaciones históricas que condicionan las percepciones y prácticas humanas. Lo que pudo constatarse en el trabajo de campo con tejedoras mapuche es que no solamente es en el mismo producto donde se está jugando la etnicidad sino también en los procesos de esa producción. Siguiendo nuevamente a Stiegler, cabe enfocarse en la relación entre técnica y etnia, más precisamente en cómo se producen esos procesos de construcción de identidades colectivas o de búsqueda de un nosotros. Un ejemplo es el grado de acomodación (lo étnico) de estas mujeres al mercado (lo técnico) implicando una objetivación de la técnica en que el grupo juega un papel activo. Sin embargo, como se ha demostrado aquí, y dado el grado de heterogeneidad de estos grupos, ese proceso de acomodación no se da igual en todas las tejedoras. Muchas de ellas replican lo que se le enseña y se les exige desde las instituciones comerciales, desplegando una mera repetición de las prácticas en vez de un devenir. Las imágenes identitarias, las normas textiles y las representaciones étnicas que componen el repertorio cultural de una etnia son signos, pero que no refieren a un pasado común que contendría la esencia original del grupo, sino que remiten a una proyectada similitud en el proceso abierto de la actividad del tejido. En este sentido, la identidad étnica, en cuanto convencional, es siempre una identidad pretendida, fingida o deseada que no representa una esencia que ya es, o que ya fue, sino una tendencia que se despliega en la actividad del tejido. Por ello, el concepto constructivo de etnia de los Comaroff, que sitúa la etnicidad en el presente de la construcción de un signo que represente lo común, es insuficiente, a pesar de darle un lugar a la multiplicidad y la flexibilidad de las identificaciones. Es necesario darles un lugar más central, de modo que se comprenda la etnicidad como un operador radicalmente vinculado al porvenir. El signo étnico no presenta a la colectividad sino que la proyecta, generando similitudes potenciales que se actualizan en el futuro de la actividad.

Se habla comúnmente de "heredar" una tradición, o de la "transmisión" de una memoria colectiva a través de estas prácticas folclóricas. Pero si el grupo étnico no tiene sino un origen mítico, entonces tenemos que al mismo tiempo no hay un origen verdaderamente efectivo, y hay una tendencia a retroproyectar el porvenir en la forma de un pasado. La identidad étnica es atribuida y autoatribuida, proyectando similitudes y representándolas retrospectivamente, y como tal la etnicidad viene a ser efectivalmente performativa, actuando en un presente abierto. Referimos a la noción de un hacer memoria desde marcos sociales que otorgan estabilidad (Halwbachs) o en el sentido de Stiegler de generar etnia a partir de la sistematicidad de la técnica que da convencionalidad. Pero 
tanto los recuerdos colectivos como las identidades étnicas involucran un trabajo de toma de posición de cada tejedora frente a una situación en la que intervienen diversos factores técnicos. Nuestra investigación de las prácticas actuales en torno al tejido mapuche permite reconocer la incidencia de estos factores técnicos, pero igualmente demuestra que ellos se articulan en el proceso identitario que está en juego en cada tejedora de modo singular. La propuesta de este trabajo consistiría en reconsiderar la idea de etnicidad o más generalmente de identidades étnicas no como algo "heredado", preexistente, sino en el sentido más dinámico de la etnicidad como un operador de transformación en el devenir de los sujetos y grupos, poniendo énfasis en la búsqueda de un "nosotros" no como origen sino como proyecto.

\section{Conclusión}

Si nos representáramos el proceso etnográfico como una formación conjunta entre el terreno y el concepto, cabría concebir el presente estudio sobre las tejedoras de la Araucanía como un intento de confrontar, con el terreno, el concepto de etnicidad que domina en la investigación y la teorización antropológica. El resultado sería una alteración radical de este concepto, pues el trabajo de campo (terreno) con tejedoras de la Araucanía ha conducido a reorientar la mirada con respecto a la etnicidad, y de ahí el título de este artículo. Pero no se trata simplemente de proponer un concepto contemporáneo de etnicidad, de acomodar la noción clásica de etnicidad a los cánones constructivistas de la actualidad, cosa que los Comaroff ya han sabido hacer (Saperstein, Penner \& Light, 2013), sino de contraponerle su otro a la noción de etnicidad, de dejarlo modificarse por lo que esta niega, a saber, la diferencia. En efecto, el terreno ha podido abrirse paso a los conceptos dominantes de los investigadores, introduciendo el sentido de diferencia interior en la experiencia de etnicidad de estas mujeres de la Araucanía. Una diferencia que, exteriorizándose en el tejido por el medio técnico, e internalizándose en la textura íntima de la subjetividad de estas mujeres, torna problemática la experiencia de lo común. De ahí que cabe, por lo tanto, pensar la identidad étnica no como representación de una similitud real, ni tampoco como mera construcción ficcional, sino como representación del espacio abierto de diputas entre proyectos de similitud; la identidad étnica como proyecto. El análisis del campo etnográfico, formación común de terreno y concepto, avanza desde el cuestionamiento de los conceptos dominantes a la elaboración de un concepto de etnicidad que permite destacar la operación de las diferencias, para concluir aplicando dicho concepto al material que lo ha informado.

Es así como, según lo expuesto, en el caso de estas tejedoras mapuche, la etnicidad sería un proceso que está en un permanente devenir. Dicho devenir involucraría una continua tensión entre construcciones identitarias y las técnicas propias del contexto social del tejido. Se ha analizado un primer escenario, microgenético, en que esta tensión se caracteriza por una articulación no libre de conflicto entre identidad y la técnica misma del tejido. En el segundo escenario analizado, centrado en los circuitos macrogenéticos del tejido mapuche actual, observamos que los procesos identitarios, las técnicas comerciales y religiosas del contexto mapuche se relacionan entre sí en una transmutación permanente. Puede decirse a la luz de estas observaciones que el fenómeno étnico en el tejido mapuche involucra una tensión entre identidad y técnica, que por lo mismo requiere un concepto que no afirme una esencia anclada en un pasado mítico, ya cerrada, terminada, homogénea, única, aplicada por igual; sino que explique los efectos de identificación y de generación de etnias en términos de individuación y de diferenciación de un devenir, donde las identidades colectivas constituyen proyectos culturales de comunidad. Esto implica que tampoco tiene sentido pensar en la repetición de las identidades étnicas antiguas o "resurgidas", ya que la repetición, siempre diferencial, es permanente transmutación. En el caso de estos grupos de tejedoras las transmutaciones ocurren en diversos estratos: el paso de una religión a otra; adquisición de nuevas reglas de tejido; apertura del textil al circuito comercial. Sin embargo, esta fluidez y dinamismo no es apreciable a simple vista, ya que la imagen dominante que se ofrece de las tejedoras, tanto para el extranjero que compra el textil como para las propias tejedoras, remite a una idea romántica del indígena del pasado. La imagen dominante recubre la diferenciación cultural bajo un signo unitario, cerrado, y por tanto homogeneizante. La misma eficacia tienen los signos étnicos que regulan el devenir del tejido.

Este trabajo ha discutido el concepto de etnicidad con el fin de contribuir a ahondar en un fenómeno complejo que está lejos de manifestarse como simple homogeneidad o de poder explicarse por la existencia de una esencia cultural. En este sentido, el concepto de etnicidad como un repertorio que transparenta la similitud de una conciencia colectiva, si bien da cuenta de una concepción más dinámica que aquellas que suponen la anterioridad de una esencia común, todavía no permite dar cuenta de la tensión y la diferencia como el elemento fundamental en la subjetividad de las tejedoras mapuche. Para dar cuenta de la densidad de matices y multiplicidad de tomas de posición en la experiencia de las tejedoras, la discusión realizada sugiere que es importante enfatizar una mirada a la etnicidad como un proceso en permanente devenir, en el cual la memoria social de un grupo reconduce una selección interesada de experiencia pasadas y tradiciones para orientar la construcción de una no efectiva sino virtual identidad futura, o sea, una identidad potencial. 


\section{Alteração do conceito de etnicidade a partir da experiência das tecedoras mapuche do sul do Chile}

Resumo: 0 caso das tecedoras mapuche da 9a Região do Chile nos permite reconsiderar os fenômenos de identidade cultural e etnicidade à luz das tensões e dos processos de subjetividade que medeiam a construção da memória cultura. São analisados tanto o cenário microgenético dos trabalhos de identidade quanto um cenário macrogenético, nos quais os processos identitários, as técnicas comerciais e religiosas do contexto mapuche se relacionam em permanente transmutação. Discutese o conceito de etnicidade com o objetivo de aprofundar a compreensão de um fenômeno que está longe de manifestar-se como uma simples homogeneidade. A discussão procura abordar a multiplicidade de tomadas de posição na experiência das tecedoras, enfatizando um olhar para a etnicidade como um processo em permanente devir, no qual a memória social do grupo reconduz uma seleção interessada de tradições orientando a construção de uma identidade potencial face ao porvir.

Palavras-chave: identidade étnica, indígenas, psicologia social, memória social.

\section{Alteration of the concept of ethnicity from the experience of the Mapuche weavers in southern Chile}

Abstract: The case of Mapuche weavers from the IX Region of Chile allows us to reconsider the phenomenon of cultural identity and ethnicity in light of the tensions and subjectivity processes that mediate the construction of cultural memory. We analyze both a microgenetic scenario of identity works and a macrogenetic scenario where identity processes and commercial and religious techniques of Mapuche context relate to each other in constant transmutation. The concept of ethnicity is discussed to contribute to shed light into a phenomenon that is far from manifest itself as a simple homogeneity. A discussion is made considering the multiplicity of position statements on the experience of the weavers, emphasizing a look at ethnicity as a process in constant development, in which the social memory of the group shapes a biased selection of traditions that guides the building up of a potential identity facing the future.

Keywords: ethnic identity, indigenous, social psychology, social memory.

\section{L'altération du concept d'éthnicité à partir de l'expérience des tisseuses "mapuche" au sud du Chili}

Résumé: Le cas des tisseuses "mapuche" de la IX Région du Chili nous permet de reconsidérer les phénomènes de l'identité culturelle et de l' éthnicité à la lumière des tensions et des processus de subjectivité qui médiatisent la construction d'une mémoire culturelle. On analyse une scène microgénétique des travaux d'identité aussi bien que la scène macrogénétique où les processus identitaires, les techniques commerciales et religieuses du contexte "mapuche" se rapportent entre eux dans une transmutation permanente. On débat le concept d'éthnicité pour contribuer à l'approfondissement dans un phénomène complexe qui est loin de se manifester comme une simple homogénéité. Pour reconnaître la densité des nuances et de la multiplicité de choix à l'expérience des tisseuses, la discussion réalisée suggère qu'il faut souligner le regard sur l'éthnicité comme processus en évolution constant, où la mémoire sociale d'un groupe reconduit à une sélection intéressée des traditions pour orienter la construction d'une identité potentielle à l'attente du futur.

Mots-clés: identité ethnique, indigène, psychologie sociale, mémoire sociale.

\section{Referências}

Bajtin, M. (1982). Estética de la creación verbal. México: Siglo Veintiuno.

Bajtin, M. (1989). Teoría y estética de la novela: Trabajos de investigación. Madrid:

Taurus.

Barth, F. (1969). Los grupos étnicos y sus fronteras. México: Fondo de Cultura Económica.

Bengoa, J. (2003). Historia de los antiguos mapuches del sur. Desde antes de la llegada de los españoles hasta las paces de Quilín. Santiago de Chile: Catalonia.

Brewer, M. B., Weber, J. G., \& Carini, B. (1995). Person memory in intergroup contexts: Categorization versus individuation. Journal of Personality and Social Psychology, 69, 29-40.

Brubaker, R. (2009). Ethnicity, Race, and Nationalism. Annual Review of Sociology, 35, 21-42.

Campbell, D. T. (1958). Common fate, similarity, and other indices of the status of aggregates of persons as social entities. Behavioural Sciences, 3, 14-25.

Comaroff, J. L. (1994). Etnicidad, violencia y política de identidad. Temas teóricos, escenas sudafricanas. In J. P. Fernández de Rota (Ed.). Etnicidad y violencia [Simposio] (pp. 205-225). A Coruña: Universidade, Servicio de Publicación. 
Comaroff, J. L., \& Comaroff, J. (2012). Etnicidad S.A. Buenos Aires: Katz.

Dasgupta, N., Banaji, M. R., \& Abelson, R. P. (1999). Group entitativity and group perception: Associations between physical features and psychological judgment. Journal of Personality and Social Psychology, 77, 991-1003.

Denson, T. F., Lickel, B., Curtis, M., Stenstrom, D. M., \& Ames, D. R. (2006). The roles of entitativity and essentiality in judgments of collective responsibility. Group Processes \& Intergroup Relations, 9(1), 43-61.

Dillehay, T. D. (2004). Monte Verde: un asentamiento humano del pleistoceno tardio en el sur de Chile. Santiago de Chile: LOM.

Eidheim, H. (1976). Cuando la identidad étnica es un estigma social. In F. Barth (Ed.), Los grupos etnicos y sus fronteras (pp. 50-74). Mexico: Fondo de Cultura Económica.

Gaertner, L., \& Schopler, J. (1998). Perceived ingroup entitativity and intergroup bias: An interconnection of self and others. European Journal of Social Psychology, 28, 963-980.

Gillis, J. (1994). Memory and identity: The history of a relationship. In J. Gillis (Ed.), Conmemorations, the politics of national identity (pp. 3-24). New Jersey: Princenton University Press.

Haaland, G. (1976). Factores económicos determinantes en los procesos étnicos. In F. Barth (Ed,), Los grupos etnicos y sus fronteras (pp. 75-95). México: Fondo de Cultura Económica.

Halbwachs, M. (2004). Los marcos sociales de la memoria. Barcelona: Anthropos.

Haye, A. (2012). Beyond recollection: Toward a dialogical psychology of collective memory. Culture \& Psychology, 18(1), 23-33.

Instituto Nacional de Estadísticas (2012). Resultados preliminares censo de población y vivienda 2012. Santiago, Chile: INE.

Jaspal, R., \& Cinnirella, M. (2012). The construction of ethnic identity: insights from identity process theory. Ethnicities, 12(5), 503-530.

Kastoryano, R., \& Schader, M. (2014). A comparative view of ethnicity and political engagement. Annual Review of Sociology, 40, 241-60.

Meer, T., \& Tolsma, J. (2014). Ethnic diversity and its effects on social cohesion tom. Annual Review of Sociology, 40, 459-78.

Mege, P. (1987). Los símbolos constrictores: una etnoestética de las fajas femeninas mapuches. Boletín del Museo de Arte Precolombino, 2, 89-128.

Mege, P. (1989). Los símbolos envolventes: una etnoestética de las mantas mapuches. Boletín del Museo de Arte Precolombino, 3, 81-114.
Mege, P. (1990). Arte textil Mapuche. Santiago, Chile: Museo Chileno de Arte Precolombino.

Mege, P. (1992). Colores en la cultura Mapuche. In Colores de América. Santiago, Chile: Editorial Museo Chileno de Arte Precolombino.

Mege, P. (1997). La imaginación araucana. Santiago, Chile: Editorial LOM.

Oliveira, R. C. de. (2007). Etnicidad y estructura social. México: CIESAS.

Okamoto, D., \& Mora, C. G. (2014). Panethnicity. Annual Review of Sociology, 40, 219-39.

Paolicchi, P. (2000). Recordar y relatar. In A. Rosa, G. Bellelli \& D. Bakhurst (Eds.), Memoria colectiva $e$ identidad nacional (pp. 279-306). Madrid: Biblioteca Nueva.

Saperstein, A., Penner, A., \& Light, R. (2013). Racial formation in perspective: Connecting individuals, institutions, and power relations. Annual Review of Sociology, 39, 359-78.

Schraml, C. (2014). How is ethnicity experienced? Essentialist and constructivist notions of ethnicity in Rwanda and Burundi. Ethnicities, 14(5), 615-633.

Stiegler, B. (1994). La técnica y el tiempo (Tomo 1). Argitaletxe Hiru: Cultura Libre.

Sweeney, M., \& Raley, R. (2014). Race, ethnicity, and the changing context of Childbearing in the United States. Annual Review of Sociology, 40, 539-58.

Tajfel, H., \& Turner, J. (1979). An integrative theory of intergroup conflict. In W. G. Austin \& S. Worchel (Eds.), The social psychology of intergroup relations (pp. 33-48). Monterrey, CA: Brooks-Cole.

Thompson, J. B. (2002). Ideología y cultura moderna: teoría crítica social en la era de la comunicación de masas. México, DF: Universidad Autónoma Metropolitana.

Van Dijck, J. (2004). Mediated memories: Personal cultural memory as object of cultural analysis. Continuum, 18(2), 261-277.

Yinger, J. M. (1985). Ethnicity. Annual Review of Sociology, $11,151-80$.

Yzerbyt, V., Corneille, O., \& Estrada, C. (2001). The interplay of subjective essentialism and entitativity in the formation of stereotypes. Personality and Social Psychology Review, 5, 141-155. 